\title{
Manifestaciones neurológicas de la infección por VIH en pediatría
}

\author{
Sandra Serrano V.!
}

\section{Neurologic abnormalities in children with HIV infection}

\begin{abstract}
Neurologic symploms are frequenlly detected in children with HIV infection and some times they ore the first evidence of the disease. Nervous syslem compromise in such patients may be due to a direct action of the HlV on neural tissues or a consequence of the immune defikiency, through secondory viral, bacterial, parosytic or fungal, uncontrolled infeclions, lumors or cerebrovascular accidents associaled wilh immune vosculitides of thrombocytopenia. The firsl mechanism is more frequent in children, parlicularly when they are infected early in life, while the second one is more usual in adults. Hiv has neurothropic properties and is able to locate in microglia and macrophage cells of the nervous system, cousing acute meningoencephalitis, subocute usually progresive encephalopathy, myelitis, peripheral neuropathy and miopalhy. Mosl importanl dinical signs and symptoms of Hlv sncephalopalhy in children are psychomotor relordalion. losl or absent progression of acquired skilts, acquired microcephalus, progresive pyamidal tracl signs, and atlentional deficit. Trealment with immune globuline and zidovudine offers some favorable possibilities.
\end{abstract}

[Key words: HIV, AIDS encephalopathy, neuritis, myditis.)

La frccuencia con que se describcn altcraciones neurologicas en pacientes infectados con el virus de inmunodeficienciá humana varía de 30 a $90 \%$; la más baja corresponde a adultos con infección asintomática y la más alta a niños en ctapa sintomálica. Ellas pueden ser la primera manifestación de la enfermedad en un número no despreciable de casos. Hasta 1984 se creía que las manifestaciones neurológicas relacionadas con el VIH eran debidas a la inmunodeficiencia $y$, por lo tanto, a infecciones concurrentes o neoplasias, pero ahora se sabe que cl VIH es neurotropo y también es capaz de dañar -por si mismo- el tejido nervioso, aun antes de que aparezcan manifestacioncs de inmunodeficiencia. Hay cvidencia clínica y experimental de la presencia activa del virus en el sistema nervioso, que ha sido aislado del líquido cefalorraçuídeo (LCR), el ccrebro, la médula espinal y nervios periféricos ${ }^{1-7}$.

1. Departamento de Especialidades, Facultad de Medicina, Universidad de Concepción.

\section{Afecciones neurológicas por acción directa del VIH}

El mecanismo exacto por el cual el virus daña el sistema nervioso, se desconoce. La infección por el VIH cstá confínada en cl cerebro casi exclusivamentc a la microglia y los macrófagos ${ }^{\beta}$. No se ha demostrado en forma consistente en otros tipos de células nerviosas como neuronas u oligodendroglia. El virus induciría una activación relativa de la inmunidad, como consecuencia de la cual se liberarian ciertas sustancias neurotóxicas, entre éstas las citoquinasas, la interleuquina $1 \mathrm{y}$ cl factor alla de necrosis tumoral. Esta inmunoactivación sostenida sería responsable, por lo menos en parte, de daño en la mielina, las neuronas y los otros componentes del encéfal ${ }^{9-12}$. A continuación se describen algunas de las afecciones neurológicas provocadas por acción directa del virus VIH sobre el sistcma nervioso.

La meningoencefalitis aguda ocurre en clapa precoz de la infección, coincidiendo con el viraje serológico. Se presenta como cualquicr meningitis asćptica, con fiebre, irritabilidad, rigidez de nunca y alteraciones leves del líquido cefalorraquídeo. Evoluciona hacia la recuperación espontánea pero 
puede reaparccer. Se ha descrito también en recién nacidos ${ }^{13}$.

La encefalopatía subaguda es cl trastorno ncurológico más frecuente. Al comienzo sus manifestaciones pueden ser sutiles y pasar inadvertidas. Los primeros síntomas pueden consistir en alteraciones leves de la memoria, cefaleas, signos de desinhibición frontal, temblor fino, debilidad generalizada e hipereflexia, para dar paso luego a signos piramidales bien definidos. La afectación de los nervios periféricos y la incontinencia de esfínteres pueden aparecer en cualquier momento. Con el avance de la enfermedad se produce deterioro psíquico y orgánico progresivo.

En la mielitis los síntomas más frecuentes son paraparesia e incontinencia de esfínteres de instalación subaguda. En el examen físico, además de paraparesia espástica, suelen encontrarse deficiencias en la sensibilidad profunda y vibratoria. Las lesiones anatomopatologicas se han descrito especialmente en la médula torácica media e inferior, siendo posible en algunos casos aislar el virus VIH. El diagnóstico diferencial debe hacerse con otras afecciones medulares susceptibles de tratamiento quirúrgico o antiviral.

Como en el caso de la encefalitis y la mielitis, la neuritis periférica puede ser la primera manifestación de la infección por VIH. Su espectro es muy amplio, incluye las de distribución sensorial, sensoriomotriz y autonómica. Se ha descrito una forma de neuropatía motora progresiva en pacientes adultos con infección por VIH, con características clínicas y electrofisiológicas similares al sindrome de Guillain Barre, en todos los cuales la recuperación fuc tota ${ }^{3}$. Recientemente se describió un caso de polineuropatía inflamatoria desmielinizantc en un niño de cinco años con infección sintomática por $\mathrm{VIH}$, con recuperación motora casi completa a los 8 meses de seguimiento ${ }^{14}$. La miopatía asociada a la infección por VIH se caracteriza por debilidad motora proximal y alteraciones electromiográficas propias de daño miopático.

\section{Afecciones neurológicas derivadas del estado de inmunodeficiencia}

Las afecciones neurológicas derivadas del estado de inmunodefíciencia pueden ser causa. das por infecciones, trastomos vasculares o neoplasias.
Entre los agentes que con mayor frecuencia provocan infecciones en los pacientes de SIDA están los virus (citomegalovirus, varicela zoster, papova virus), bacterias (Haemophilus influenzae, Sireptococcus pneumoniae, Mycobacterium tuberculosis, Treponema pallidum, Escherichia coli), parásitos (Toxoplasma gondii, Tenia solium), hongos (Cryptococcus neoformans, Candida albicans).

Los virus provocan encefalitis o mielitis. Las bacterias por lo general producen meningitis, siendo poco frecuentes los abscesos. El Treponema pallidum puede afectar al encéfalo, las meninges o la médula espinal. Los parásitos suclen ocasionar enccfalitis o abscesos cerebrales. El $T$. gondii puede causar encefalitis subaguda progresiva o bien abscesos. En pacientes inmunocompetentes el toxoplasma produce árcas necrólicas rodeadas de intensa reacción inflamatoria mononuclear; en cambio en el inmunodeficiente, en quien la letalidad es de $70 \%$, la reacción mononuclear es escasa, lo que podría explicar la persistencia de la infección y las lesiones necróticas difusas.

Los hongos que con mayor frecuencia producen infecciones del sistema nervioso en pacientcs con sida son los mencionados previamente. El Cryptococcus neoformans suele producir meningitis, aunque también puede causar abscesos cerebrales únicos o múltiples. La meningitis se caracteriza por fiebre, cefalea y confusión mental; sin embargo, los signos meníngeos son escasos y las alteraciones del líquido cefalorraquídeo suelen ser mínimas. El diagnóstico se hace observando el hongo en el líquido cerebroespinal mcdiante tinción con tinta china a por detección de antigenos con una prueba de látex. La infección del sistema nervioso por Candida albicans suele presentarse como abscesos en que el hongo es el único agente infectante o bien en asociación con $r$. gondii o Staphylococcus epidermidis. El diagnóstico se basa en la identificación del hongo en el líquido cerebroespinal.

Las causas vasculares de afectación del sistema nervioso en el síndrome de inmunodeficiencia adquirida tienen su origen en fenómenos de vasculitis o de trombocitopenia autoinmune en asociación con los cuales se producen accidentes vasculares hemorrágicos $o$ isquémicos.

Entre las neoplasias del sistema nervioso en pacientes con infección por VПH destacan los 
linfomas y el sarcoma de Kaposi. Los linfomas pucden ser primarios del cncéfalo o metâstasis de linfomas sistémicos.

\section{Manifestaciones neurológicas en los niños con infección por VIH}

Las manifestaciones neurológicas en los niños con infección por VIH son diferentes, según la edad en que esta sc adquiere. Si ello ocurre en un escolar o adolcscente, son parecidas a las del adulto y predominan las causadas por el estado de inmunodeficiencia; en cambio, cuando suceden en los primeros años de vida obedecen en su gran mayoría a cncefalopatía subaguda provocada por acción directa del virus VIH sobre el sistema nervioso central. Las complicaciones derivadas del estado de inmunodeficiencia, a diferencia de lo que ocurre en el adulto, son más raras. Así, pues, los accidentes vasculares y las neoplasias se presentan con frecuencias que no superan 5\% $3-5,7.15$.

Los niños infectados por $\mathrm{cl}$ VIH en el útero o poco después de nacer pueden permanecer sin síntomas neurológicos por meses o aun por varios años (en algunos casos, las primeras manifestaciones neurológicas han aparecido a los 5 años de edad); sin embargo, en la mayoría de los casos la evidencia de encefalopatía ya está presente a los 18 meses de edad. Una de las más precoces puede scr retraso en el desarrollo psicomotor ${ }^{15}$. La interpretación de éste debe ser cuidadosa, pues si bicn puede obedecer a encefalopatía en cvolución, puede también ser consecuencia de la suma de varios factores, como exposición a cirogas en el útero, infecciones matemas repetidas y un ambiente social desfavorable. Más tarde los primeros síntomas suelen expresarse como deterioro en el juego, enlentecimiento en la adquisición y luego pérdida de habilidades psicomotoras, especialmente las relacionadas con funciones cognitivas y de lenguaje. Paralelamente, el perímetro de cráneo deja de aumentar o lo hace más lentamente que lo normal, dando origen a microcefalia. Precozmente o en el curso de la evolución aparece alteración motora piramidal, bilateral, progresiva. AI comienzo puede manifestarse sólo como hiperreflexia con clonus aquiliano, pero luego da paso a paraparesia o tetraparesia espástica. Los signos piramidales han sido descritos hasta en $85 \%$ de los pacientes pediátri- cos con encefalopatía por VIH. A medida que la cnfermedad avanza, la mayoría sufre afectación de las cuatro extremidades, asociada en algunos casos a disfagia, disartria, ataxia o rigidez extrapiramidal. El déficit atencional hiperactivo no es infrecuente en niños con infección VIH en edad escolar. Las convulsiones son infrecuentes, ocurren en no más de $10 \%$ de los pacientes, la mayoría en relación a cuadros fcbriles. En dos de 20 niños con encefalopatía progresiva se han descrito contracciones mioclónicas no asociadas a descargas paroxísticas o periódicas cn el electroencefalograma. La encefalopatía progresiva pucde seguir un curso rápido, lento -pasando por períodos de estabilización variables, en los cuales el niño no adquiere ni picrde habilidades-o estático. Excepcionalmente se ha observado discreta mejoría cspontánea de la condición neurológica. La forma más frecuente de cvolución espontánea es la progreșiva, con o sin periodos estables, siendo ésta la de peor pronóstico vital. Si se reúnen dos de las scries publicadas, de 68 y 36 niños, respectivamente, $70 \%$ de los que tenian encefalopatía siguieron un curso progresivo y $52 \%$ de ellos fallecieron 1 a 23 meses después de comenzar las manifestaciones de progresión. Por cl contrario, hasta el término de ambos estudios, ninguno de los niños con curso estable o sin sintomas neurológicos había muerto. En general hay una relación directa entre la afección neurologica y la severidad de la inmunodeficiencia; sin cmbargo, puede haber daño neurologico progresivo en niños con síntomas inmunológicos mínimos o sin ellos y una asociación significativa entre encefalopatía progresiva y ausencia de anticuerpos séricos neutralizantes ${ }^{4,5}$.

E1 líquido cefalorraquídeo se encontro alterado en 6 a $38 \%$ de los casos afectados en dos series de niños con encefalopatía progresiva. Las alteraciones consistieron en discreto aumento de la albúmina (52 a $80 \mathrm{mg} / \mathrm{dl})$ y pleocitosis de predominio linfocitario, no mayor de 52 elementos. Los títulos de anticuexpos VIH en LCR pueden duplicar los séricos en algunos pacientes con encefalopatía progresiva y aun en niños sin síntomas neurológicos, sugiriendo síntesis de anticuerpos contra la barrera hematoencefalic ${ }^{4}, 5$. La detección de secuencias provirales, mediante reacción de polimerasa en cadena, en células nucleadas de líquido cefalorraquídeo de pacientes VHH positivos, muestra clara correlación con la 
presencia de enfermedad neurológica, de cuya existencia informaria de manera precoz, rápida y directa ${ }^{16}$.

El hallazgo más frecuente en la tomografía axial computadorizada de cráneo es la atrolia cerebral, con aumento secundario del espacio subaracnoideo y ventricular, que se observa en casi todos los nitros con encefalopatía progresiva, en $60 \%$ de los con curso estable y puede preceder las manifestaciones neurológicas. Otro hallazgo frecuente en estos pacientes son las calcificaciones bilatcrales y simétricas en los núcleos basales y la sustancia blanca periventricular ${ }^{5}$. La resonancia nuclear magnética, en general, no ofrece ventajas significativas sobre la tomografía axial de cráneo ${ }^{17}, 18$, ya que, si bien permite evaluar mejor las alteraciones de mielinización, la tomografía muestra mcjor las calcificaciones.

En adultos sintomáticos sin manifestaciones newrológicas, que no eran bebedores crónicos, se encontraron alteraciones significativas en los potenciales evocados de tronco cerebral, por lo que se ha propuesto que este examen podría detectar precozmente el compromiso nervioso ${ }^{19}$.

Los hallazgos neuropatológicos característicos de la encefalopatía por VIH son disminución del peso cerebral en relación a la edad; infílıado de células inflamatorias con células gigantes multinucleadas; astrocitosis difusa de la sustancia blanca; inflamación y calcificaciones vasculares a nivel de los ganglios basales y sustancia blanca periventricular, corresponden a las calcificaciones que se ven en la tomografía axial. En la médula espinal se observa, en algunos casos, degeneración de los tractos corticocspina$\mathrm{les}^{5}, 20,21,23$. En 15 niños fallecidos por SIDA, 14 con marcados signos de compromiso piramidal de duración e intensidad variable, el examen de la médula espinal mostró cambios patológicos de los tractos corticoespinales en 10 casos; en cuatro de tipo axonopatía con compromiso del axón y la mielina; en los restantes la mielinización era pobre, con preservación del axón. Estos últimos podrían corresponder a retraso en la mielinizacion, o bien a injuria -posiblemente mediada por citoquinasas- sobre la miclina recićn formada, ya que los tractos corticoespinales son los últimos en mielinizarse en la médula espinal. En estos pacientes no se encontró mielopatía vacuolar, como la observada en adultos con SIDA 22 .
En lo que respecta al tratamiento, por lo general se ha obscrvado una respuesta favorable, a veces muy notoria, a la gamaglobulina y la zidovudina. Se han mostrado aumentos significativos en las calificaciones obtenidas en pruebas cognoscitivas en niños con enfermedad avanzada por VIH tratados con zidovudina oral y por infusión continua. Los niños menores de 30 meses, examinados con las escalas de Bayley, mostraron los cambios más importantes en las primeras seis semanas de uratamiento ${ }^{2426}$. Mejorías comparables se han observado también en adultos con enfermedad avanzada. La mejoría podría deberse a un efocto directo de la zidovudina sobre el sistema nervioso central o bien ser el resultado de un mejoramiento en el estado general. Existe un estudio con dideoxynosina cuyos resultados son difíciles de interpretar ${ }^{27}$.

\section{Resumen}

Hasta $90 \%$ de los niños con infección sintomática por VIH pueden tener manifestaciones de daño neurológico, las que en ciertos casos son la primcra expresión de la enfermedad. Ellas pueden ser causadas directamente por el virus o como consecuencia de la deficiencia inmune que produce, caso en el cual los responsables son otros agentes infecciosos, tumores o accidentes vasculares debidos a vasculitis o trombocitopenia. El virus se ubica en la microglia y en los macrófagos del sistema nervioso, causando meningoencefalitis aguda, encefalopatía subaguda de curso frecuentemente progresivo, mielitis, neuropatía periférica y miopatía. Las manifestaciones clínicas más importantes de encefalopatía por VIH son el retraso psicomotor, la pérdida o falta de progresión de habilidades adquiridas, microcefalia adquirida, síntomas progresivos piramidales y déficit atencional. En los niños más pequeños, a diferencia de lo que ocurre en adultos y adolescentes, el compromiso neurológico secundario al estado de deficiencia de la inmunidad es menos frecuente que el calisado por efecto directo del VIH. El tratamieniu con gamaglobulina y especialmente la zidovudina ofrece algunas perspectivas faverables.

(Palabras clave: VIH, SIDA, encefalopatía, neuropalía, mielitis, líquido cerebroespinal.) 


\section{Referencias}

I. Koppel B, Wormser $G$, Tuchman A, et at: Central nervous system involvement in palients with acquired immunodeficiency syndrome. Acta Neurol Scand 1985 ; 71: 337-353.

2. Levy $R$, Bredesen D, Rosenblum $M$ : Neurologic manifestation of the acquired immunodeficiency syndrome (AIDS): Experiency at UCSF and review of the literature. J Neurosurg 1985; 62: 475-495.

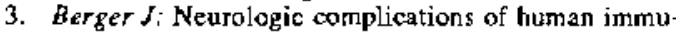
nodeficiency virus infection. Posgraduate Medicine 1987; 81: 72-79

4. Epstein L. Sharer L, Oleske J, et al.: Ncurologic manifestation of human immunodeficicncy vinus infection in children. Pediatrics 1986; 78: 678-687.

5. Belman A, Diamond G. Dickson $D$, et al.: Pcdjatric acquired immunodeficiency syndrome. Neurologic syndromes. Am J Dis Child 1988: 142: 29-35.

6. Cogo A: The europian collaborative study. Neurologic signs in young children with human immunodeficiency vins infection. Pediatr Infect Dis J 1990; 9: 402-406.

7. Schmidi B, Seeger J, Kreuz W, et al.: Central nervous systcm involment of children with IIIV infection. Dev Med Child Neurol 1991; 33: 535-540.

8. Birkmann R, Schwinn A, Narayan O, et al.: Human immunodeficiency virus infection in microglia: Correlation belween cclls infected and cclls cultured from infectious brain tissue. Ann Neurol 1992; 31: 361.365 .

9. Tyor W, Glass J, Griffin J, et al.: Cylokine expression in the brain during the adquired immunodeficiency syndrome. Ans Neurol 1992; 31:349-360

10. Gallo P, Laverda A, De Rossi $A$, et al,: Immunonological markers in the cerebrospinal fuid of HIV-1 infected children. Acta Pediatr Scand 1991: 80: 659666.

11. Grimaldi $L$, Martino $G$, Franciorra $D$, et al.. Elevated alpha-tumor necrosis faclor levels in spinal fluid from HIV-]-infected paticnts with central nervous system involvement. Ann Neurol 1991; 29: 1068-1072.

12. Heyes $M$, Brew B, Mariin A, et al.: Quinolonic acid in cererospinal fluid and scrum in IIIV.1 infection: relationship to clinical and neurological status. Ann Neurol 1991; 29; 202-208.

13. Strugo J, Wittek A, Israel B, and Brunell P: Meningoencephalitis in a neunate congenitally infected with HIV-1. I Pedialr 1992; 120: 93-95.
14. Raphael S, Price M, Lischner $H$, es al.: Inflamatory demyclinating polyneuropathy in a child with symptomatic HIV infection. J Pediats $1991 ; 118: 242$ 245.

15. Butler C. Hittelman J, Hauger S: Approach to neuto. devclopment and neurologic complications in pediatric HIV infection. J Pediatr 1991; 119: 54 l-546.

16. Shaunak $S$, Albright $R_{f}$ Klotman $M$, et al : Amplification of HIV-I provirus from cerebrospinal fluid and its comelytion with neurologic diseasc. I Infect Dis 1990 161: 1068-1072.

17. Barber $C$. Rowlands P, McCarthy $M$, et al.: Clinical utility of cranial CT in HIV positive and SIDA patients with neurological disease. 'Clin Radiol 1990; 42 : 174. 165.

18. Chamberlain $M$ : Pediatric AIDS: comparalive cranial MRI and CT scans. Pediatr Neurol 1991: 7: $357-362$.

19. Pagano M, Cahn P, Garan M, et al,: BAEPs in HГV seropositives patients with and withoul SIDA. Arch Neurol 1992; 49: 166-169.

20. Tovo P, Gabiano $C, J$ kng S, et al.: Brain atrophy with intracranialcalcification following congenital HIV infection. Acla Pedialr Scand 1988; 77: 776-779.

21. Kure $K$, Lena $J$, Lymian $W$, et at, Human immunodeficiency virus 1 infection of the nervous sysem: an autopsy study of 268 adult, pediatric and feral brains. Hum Pathol 1991; 22: 700-710.

22. Dickson D, Betmon A, Kim T, et al.: Spinal cord pathology in pediatric acquired immunodeficiency syndrome. Neurology 1989:39:227-235.

23. Epsiein L, Di Carlo P. Joshi V, et af.: Primary lymphoma of the central nervous system in children with acquired immunodefjeicncy syndrome. Pediatrics. $1988 ; 82: 355-363$.

24. Pizzo P, Eddy $I$, Fatcon $J$, et al : Effect of continuous intravenous infusion of zidovudine in childten with symptonatic HTV infection. N Eng1 J Med 1988: 319 : 889-896.

25. Matthens $J$, Walker $L$, Watson $J$, et al.: AJDS encephalopathy with response to treatment. Arch Dis Child 1988; 63 ; $545-547$.

26. McKinney $R$, Maha $M$, Connor E, el al.: A multicenter trial of oral zidovudine in children with advances boman immunodeficiency virus discase. N Lingl J Mled $1991 ; 324: 1018-1025$.

27. Butler $K$. liusson $R$, Balis $F$, et al: Dideoxynosine in children with symptomatic human immunodeficiency virus infection. $\times$ Engl J Med 1991: 324: 137-144. 